\title{
The Dynamics of Oil and Stock Prices Comovements
}

\author{
Claire G. Gilmore ${ }^{1}$, Ginette M. McManus ${ }^{2}$, Rajneesh Sharma ${ }^{2} \&$ Ahmet Tezel $^{2}$ \\ ${ }^{1}$ Department of Accounting and Finance, McGowan School of Business, King's College, Wilkes-Barre, USA \\ ${ }^{2}$ Department of Finance, Haub School of Business, Saint Joseph's University, Philadelphia, USA \\ Correspondence: Ginette M. McManus, Department of Finance, Haub School of Business, Saint Joseph's University, \\ Philadelphia, 5600 City Avenue, PA 19131, USA. Tel: 610-660-1632.
}

Received: November 17, 2015

Accepted: December 29, 2015 Online Published: January 11, 2016

doi:10.5430/ijfr.v7n1p121

URL: http://dx.doi.org/10.5430/ijfr.v7n1p121

\begin{abstract}
The dynamic relationships between crude oil prices, oil sector stock price indices and stock market price indices is examined and evidence of cointegration between these variables is found. A vector error-correction (VEC) model reveals that the stock prices of companies in the integrated oil and gas sector have a long-run negative relationship with oil prices while those in the oil and gas exploration and production sector have a long-run positive relationship with oil prices. Both indices have a long-run relationship with mid- and small-capitalization stock prices. However, following shocks to oil sector indices, oil prices tends to restore the long-term equilibrium. These findings should be useful to investors in their attempts at appropriately structure their overall portfolios.
\end{abstract}

Keywords: oil prices, oil sector stock prices, cointegration, variance decompositions

\section{Introduction}

This paper examines the short-term and long-term relationships between the price movements of crude oil, a commodity of major economic importance, and stock market prices. An understanding of interactions between commodity and equity markets is useful in portfolio diversification strategies for investors. The issue is of particular relevance in a period of great instability in stock and bond markets caused by the recent global recession and by fears of a possible future inflationary environment.

There is some research in the literature on the connections between oil spot prices and oil future prices. (Note 1) Less work has been done on the relationship between oil prices and stock market returns. It is often assumed that this relationship is negative: increases in oil prices raise costs in many industries, depressing stock prices by lowering expectations about future earnings and dividends. Alternatively, a growing economy can increase demand on oil and tend to raise stock prices. (Note 2) Both notions suggest that oil price movements should be associated with stock market returns. However, published results to date have produced conflicting assessments on the nature of this relationship and on the direction of causality. In this paper, we extend prior research by examining not only the relationships between oil prices and broad stock market prices but also their interrelationships with oil sector stock prices. Rising oil prices has increased investors' interest in trading oil-related stocks. However, this requires an understanding of the relationships between oil prices, oil sector stock prices and broad stock market prices. Findings of differences in behavior between these indices will be useful to investors in their attempts at appropriately structure their overall portfolios.

Research on oil-stock price relationships has typically been carried out using regression analysis, which provides short-term analysis of linkages. Generally, this approach concludes that oil price movements do affect broad stock market indices. However, little attention has been devoted to the analysis of their dynamic long-term interactions. Our research employs the cointegration technique, a methodology that is specifically designed for the study of the long-term interrelationships. Exploration of the long-term linkages is particularly important for investors in that it will give additional insight into the long-term benefits of portfolio diversification, which may differ importantly from what is indicated by short-term regression analysis

\section{Literature Review}

As mentioned previously, surprisingly few empirical studies have been conducted on the relationships between oil prices and developed as well as emerging stock market prices. Using regression analysis, Al-Mudhaf and Goodwin 
(1993) and Huang, Masulis, and Stoll (1996) find no relationship between oil prices and broad-based U.S. stock returns (as represented by the S\&P 500) but provide some evidence that oil futures prices have a direct impact on oil sector stock prices. In contrast, Sadorsky (1999) and Papapetrou (2001) report significant relationships between oil prices and broad-based stock returns. More recently, Hammoudeh and Eleisa (2004) and Hammoudeh, Dibooglu, and Eleisa (2004) find no relationships between oil prices and S\&P oil industry stock indices for developed stock markets using linear cointegration analysis but conclude that oil sector stock investments may be profitable in periods of high volatility in oil prices. Similarly, Maghyereh (2004) finds very weak evidence that there is a relationship between crude oil prices and stock market returns in emerging markets. However, using nonlinear cointegration analysis, Maghyereh and Al-Kandari (2007) conclude that oil prices affect stock price indices in the Gulf Cooperation Council (GCC) countries. Given that the empirical evidence on the impact of oil prices on stock market prices has been mixed, the potential and need for additional research into the oil/financial markets relationship is apparent.

In this paper, we extend the understanding of the dynamic relationships between oil prices and stock market returns by using three types of variables identified in the literature: crude oil prices, oil sector stock price indices and stock market price indices representing large, mid and small capitalization companies. A multivariate cointegration analysis is performed to investigate their short-term and long-term behavior as the relationships of oil-linked company stock prices to oil prices and to broad stock market prices is also not clear. The outcomes should increase our understanding of the long-term dynamic relationships between changes in oil prices and changes in stock market prices. A finding of significant long-term linkages between these different prices (commodity and equity) will be useful to investors interested in more appropriately structuring their portfolios. Additionally, it should provide information on cross-market behavior beneficial to investors in their diversification strategies.

The rest of the paper is organized as follows. The data are described in Section 3. Section 4 presents briefly the methodology and reports the empirical results. Section 5 contains the concluding remarks.

\section{Data and Descriptive Statistics}

Crude oil (spot and futures) prices, oil sector stock prices and stock market prices indices are obtained through FactSet Research Systems Inc., a leading provider of broad scope of data and analytics headquartered in Norwalk, Connecticut. We use daily and weekly (Wednesday-to-Wednesday) data over the period January 3, 1996 through July 21, 2010 for a total of 3800 daily and 760 weekly observations. FactSet's WTI crude oil spot is used. The S\&P 500 Integrated Oil \& Gas (INTEG) and the S\&P 500 Oil \& Gas Exploration \& Production (EXPL) price indices represent oil sector stock prices. This is because the oil industry consists of companies dealing with the exploration, production, refinement and distribution of oil and gas. Companies in the Oil \& Gas Exploration and Production index are only engaged in the exploration and production of oil and gas which includes searching for crude oil, drilling and operating wells referred to as the "upstream" or E\&P sector of the industry. Companies in the Integrated Oil \& Gas index are also involved with at least one other significant activity in the refining, marketing and transportation of oil, gas and/or refined products referred to as the "downstream" or R\&M sector of the industry. These large firms have global operations (Chevron Corp. and Exxon Mobile), are fully integrated (operate in both upstream and downstream sectors of the industry) or may concentrate in the E\&P or R\&M sector. The S\&P 500 (LCAP) index is used to proxy for large company stocks. Since many oil and gas exploration and production companies are not large capitalization firms, the S\&P mid-cap 400 (MCAP) and the S\&P small-cap 600 (SCAP) indexes are also included in the analysis. All price or level series are converted to natural logarithmic form. The returns series are then constructed as the first differences of the logged price or level series. Summary statistics for the weekly returns series are shown in Table 1.

Table 1. Summary of statistical properties of weekly index return series

\begin{tabular}{lllllll}
\hline Statistic & & \multicolumn{3}{c}{ Index Series } \\
& OILS & INTEG & EXPL & LCAP & MCAP & SCAP \\
\hline $\mathrm{N}$ & 759 & 759 & 759 & 759 & 759 & 759 \\
Mean & 0.0018 & 0.0014 & 0.0017 & 0.0007 & 0.0016 & 0.0013 \\
Median & 0.0040 & 0.0027 & 0.0020 & 0.0022 & 0.0052 & 0.0045 \\
Maximum & 0.2720 & 0.1268 & 0.1271 & 0.1018 & 0.1188 & 0.1238 \\
Minimum & -0.2326 & -0.2137 & -0.2484 & -0.1645 & -0.1952 & -0.1929
\end{tabular}




\begin{tabular}{lllllll} 
Stan. Dev. & 0.0550 & 0.0299 & 0.0437 & 0.0253 & 0.0283 & 0.0299 \\
Skewness & -0.1340 & -0.5528 & -0.0790 & -0.5291 & -0.6818 & -0.6121 \\
Kurtosis & 4.5991 & 7.0648 & 4.8173 & 6.7686 & 7.1740 & 6.6864 \\
Jarque-Bera & 83.14 & 561.18 & 124.46 & 484.56 & 609.78 & 477.17 \\
Probability & 0.0000 & 0.0000 & 0.0000 & 0.0000 & 0.0000 & 0.0000 \\
\hline Correlation & & & Index Series & SCAP \\
& OILS & INTEG & EXPL & LCAP & MCAP & SAP \\
\hline OILS & 1.0000 & & & & \\
INTEG & 0.3585 & 1.0000 & & & & \\
EXPL & 0.4454 & 0.7612 & 1.0000 & & & \\
LCAP & 0.1190 & 0.5774 & 0.5001 & 1.0000 & & \\
MCAP & 0.1573 & 0.5459 & 0.5553 & 0.9277 & 0.0000 &
\end{tabular}

Index returns are estimated as the first differences of the natural logarithm of each weekly price for the period January 3, 1996 through July 21, 2010.

OILS: WTI Crude Oil Spot Price, close

INTEG: S\&P 500 Integrated Oil \& Gas Index

EXPL: S\&P 500 Oil \& Gas Exploration \& Production Index

LCAP: S\&P 500 Index; MCAP: S\&P Mid Cap 400 Index; SCAP: S\&P Small Cap 600 Index.

Over the 1996-2010 sample period, the oil price series has the highest mean return and the highest standard deviation while the large-cap price series has the lowest mean return and the lowest standard deviation. All of the return series have nonsymmetric distributions. Negative skewness of all the return series implies a thicker lower tail, that is, the return indices are skewed to the left. The kurtosis statistics indicate that all the returns series are more peaked than a normal distribution. For a normal distribution kurtosis is equal to 3.0. The Jarque-Bera statistic confirms that none of the series are normally distributed. Table 1 also reports the average correlation statistics between the weekly returns of each pair of indices for the sample period. As expected, oil returns (OILS) are more correlated with oil sector stock returns (EXPL and INTEG) and have low correlation with broad stock returns (LCAP, SCAP, MCAP). In fact, oil (OILS) and large capitalization stocks (LCAP) return indices have the lowest correlation coefficient. The S\&P 500 Integrated Oil \& Gas (INTEG) return index has higher correlation coefficients with all stock market return indices, (especially with the LCAP and the SCAP indices). Similarly, the S\&P 500 Oil \& Gas Exploration \& Production (EXPL) return index is more correlated with all the market stock return indices than with the oil return index (especially with the MCAP index).

\section{Methodology and Empirical Results}

We apply the cointegration methodology of Johansen (1988) and Johansen and Juselius (1990), henceforth referred to as JJ, to test for the presence of long-run equilibrium relationships between the time-series variables in our system (details of the cointegration methodology are discussed in the appendix). Cointegration tests allow us to determine whether a set of endogenous variables (e.g., oil price, oil-sector stock prices and stock market prices) share a common long-run stochastic trend (have a long-term relationship), while allowing for the possibility of short-run divergences. A finding of cointegration indicates interdependence of the endogenous variables, which may be the result of economic linkages between the markets or arbitrage activity between investors.

\subsection{Unit Root Tests}

Two or more nonstationary time series are cointegrated if a linear combination of the variables is stationary. If there is such a stationary linear combination, the nonstationary series are said to be cointegrated. This stationary linear combination is referred to as a cointegrating equation, representing a long-run equilibrium relationship between the variables. If there is just one long-term relationship between the variables, they share a single route of convergence 
toward equilibrium; if there is more than one long-run relationship, there are several forces pushing toward convergence paths between the variables.

The first step in the analysis is to examine each series for the presence of unit roots, to determine if the index series are nonstationary. Nonstationarity is a precondition for cointegration; additionally, all the series must be integrated of the same order. For this, the Augmented Dickey-Fuller (ADF) test and Phillips and Perron (PP) test are applied to the levels and first differences of each series; the null hypothesis is that a series is nonstationary, so rejection of the unit root hypothesis supports stationarity. The results, using the Schwartz Information Criterion (SIC), are presented in Table 2. (Note 3) For all the level series under study the null hypothesis of a unit root is not rejected. However, when the tests are applied to the first differences of the series, the null is rejected indicating that they are stationary. Consequently all the level series are integrated of order one, that is, I(1).

Table 2. Unit root tests results for weekly indices

\begin{tabular}{|c|c|c|c|c|}
\hline \multirow{2}{*}{$\begin{array}{l}\text { Index } \\
\text { Differenc }\end{array}$} & \multicolumn{2}{|c|}{ Levels } & \multicolumn{2}{|c|}{ First } \\
\hline & $\mathrm{ADF}$ & PP & $\mathrm{ADF}$ & PP \\
\hline INTEG & -1.689 & -1.640 & $-22.462 * *$ & $-30.159 * *$ \\
\hline EXPL & -0.926 & -0.856 & $-27.714 * *$ & $-27.779 * *$ \\
\hline OILS & -1.139 & -1.104 & $-28.611 * *$ & $-28.609 * *$ \\
\hline LCAP & -2.697 & -2.687 & $-28.958 * *$ & $-28.932 * *$ \\
\hline MCAP & -2.018 & -2.019 & $-27.962 * *$ & $-27.962 * *$ \\
\hline SCAP & -1.874 & -1.878 & $-28.025 * *$ & $-28.021 * *$ \\
\hline
\end{tabular}

Unit root tests are conducted using the Augmented Dickey-Fuller (ADF) and the Phillips-Perron (PP) tests. Lag lengths and model were chosen according to the Akaike Information Criterion (AIC). The critical values are based on MacKinnon (1991).

** Significant at the 5 percent level.

\subsection{Cointegration Tests}

Once the nonstationarity requirements of the level series are met, the JJ procedure can be applied to determine whether the time series are cointegrated. This test determines the rank $\mathrm{r}$ of the coefficient matrix of a vector autoregression (VAR) model of the series, with the rank indicating whether there is cointegration, as well as the number of cointegrating relationships. Two likelihood ratio tests are used, the trace test and the maximum eigenvalue test, to determine the number of cointegrating vectors. The trace test null hypothesis is that there is a maximum of $r$ cointegrating vectors against the alternative that the number is equal to $\mathrm{n}$, the number of series in the model. That is, the null hypothesis, that $r=0$, is tested against the alternative hypothesis, $r \geq 1$. If this null is rejected, the null of $r \leq$ 1 is tested against the alternative that $r \geq 2$. If this null is rejected, the null becomes $r \leq 2$, tested against $r \geq 3$, and so on. The maximum eigenvalue test has the identical null hypothesis, while the alternative is $r+1$ cointegrating vectors.

For comparison with previous studies, we first perform bivariate $(2 \times 2)$ cointegration tests involving an oil sector price index (INTEG or EXPL) with the oil spot price series (OILS) and an oil sector price index (INTEG or EXPL) with each stock market price index (LCAP, MCAP or SCAP. We find no evidence of cointegration of the oil sector price indices on a bilateral basis with either the oil price series or with each stock market price index. Only when we proceed to a multivariate (6x6) OIL grouping model consisting of the two oil sector price series (INTEG and EXPL), the oil spot price index (OILS), and the three stock market price indices (LCAP, MCAP, and SCAP) do we find evidence of cointegration. (Note 4) The test results for the weekly series are reported in Table 3. 
Table 3. Multilateral cointegration test results for the OIL grouping model

Oil Spot Price (OILS), Oil Sector Stock Prices (INTEG, EXPL) and Stock Market Prices (LCAP, MCAP, SCAP)

\begin{tabular}{llll}
\hline & Hypotheses & Trace Test & Maximum Eigenvalue Test \\
Null & Alternative & & \\
$\mathrm{r}=0$ & $\mathrm{r} \geq 1$ & $86.44^{* *}$ & 30.94 \\
$\mathrm{r} \leq 1$ & $\mathrm{r} \geq 2$ & 55.49 & 21.94 \\
$\mathrm{r} \leq 2$ & $\mathrm{r} \geq 3$ & 33.55 & 17.70 \\
$\mathrm{r} \leq 3$ & $\mathrm{r} \geq 4$ & 15.86 & 8.05 \\
$\mathrm{r} \leq 4$ & $\mathrm{r} \geq 5$ & 7.81 & 7.44 \\
$\mathrm{r} \leq 5$ & $\mathrm{r} \geq 6$ & 0.40 & 0.40
\end{tabular}

The model assumes an unrestricted intercept in the cointegrating equation and no deterministic trend in the data. A $\log$ of one is used, based on the Schwartz Information Criterion (SIC). The $r$ denotes the maximum number of cointegrating vectors.

** Significant at the 5 percent level.

The results show that the weekly series in our OIL grouping model are cointegrated according to the trace test, although not according to the maximum eigenvalue test. The trace test suggests that there is one significant cointegrating vector in the model. This implies that there are five common stochastic trends, indicating a degree of market integration. Therefore, we conclude that there exists a stationary, long-run relationship between oil sector stock prices (INTEG and EXPL), oil prices (OILS), and stock market prices (LCAP, MCAP, and SCAP).

\subsection{Tests for the Dynamics of the OIL Grouping Model}

Since the evidence indicates cointegration for the OIL model grouping, the use of an unrestricted vector autocorrelation (VAR) model in first differences would be misspecified, as information on the long-term equilibrium relationships is lost. Therefore, the next step is to estimate a Vector Error-Correction (VEC) model. We present the cointegrating vectors, for the weekly data, normalized to the Integrated Oil and Gas sector index (INTEG) in Panel A of Table 4 and normalized to the Oil and Gas Exploration sector index (EXPL) in Panel B.

Based on the results for the weekly series, the long-run relationships for the Integrated Oil and Gas and the Oil and Gas Exploration indices can be written as follows:

$$
\text { LINTEG }=1.614 * \text { LEXPL }-1.312 * \text { LOILS }-0.490 \text { LLCAP }+3.271 * \text { LMCAP }-2.718 * \text { LSCAP }
$$

and

$$
\text { LEXPL }=0.620 * \text { LINTEG }+0.850 * \text { LOILS }+0.304 \text { LLCAP }-2.027 * \text { LMCAP }+1.684 * \text { LSCAP }
$$

Table 4. Cointegration relationships

\begin{tabular}{llllll}
\hline \multicolumn{5}{l}{ Panel A: Cointegrating Vector for the Integrated Oil and Gas Index } \\
\hline LINTEG & LEXPL & LOILS & LLCAP & LMCAP & LSCAP \\
1.000 & $-1.614^{* *}$ & $1.312^{* *}$ & 0.490 & $-3.271^{* *}$ & $2.718^{* *}$ \\
& $(-6.247)$ & $(5.058)$ & $(1.895)$ & $(-4.188)$ & $(3.341)$ \\
\hline \multicolumn{7}{l}{ Panel B: Cointegrating Vector for the Oil and Gas Exploration \& Production Index } \\
\hline LEXPL & LINTEG & LOILS & LLCAP & LMCAP & LSCAP \\
& $-0.620^{* *}$ & $-0.850^{* *}$ & -0.304 & $2.027^{* *}$ & $-1.684^{* *}$ \\
& $(-2.247)$ & $(-6.193)$ & $(-1.840)$ & $(4.708)$ & $(-3.894)$ \\
\hline
\end{tabular}

Figures in brackets indicate t-statistics.

** Significant at the 5 percent level. 
The significance and size of the coefficients on the cointegrating equation in Table 4 capture the response of each series in the VEC model to departures from the long-run equilibrium. The results indicate that both oil sector price indices are significantly, but very differently, affected in the long-run by oil prices and broad stock market prices. More specifically, the stock prices of integrated companies have a significant and negative long-term relationship to oil prices. This result is not surprising as these larger, more established and diversified firms may experience declining profit margins when oil prices increase if their activities are more on the downstream (refining and marketing) than the upstream (exploration and production) sector of the oil and gas industry. In addition, the stock prices of companies in the integrated oil and gas sector have a more significant relationship to stock prices. However, the direction of the long-run relationship is not clear as the stock prices of integrated firms are positively (negatively) related to the prices of medium (small) capitalization stocks. Thus, a one-percentage point change in the mid-cap price index could be associated with a 3.27 percent change (in the same direction) in the integrated oil and gas price index while a one-percentage point change in the oil price index could be associated with a smaller change, 1.31 percent (in the opposite direction), in the integrated oil and gas price index.

When we normalize the cointegrating vector on the oil and gas exploration and production index, there is, as expected, a positive long-run relationship with oil prices. The stock prices of E\&P companies are also more significantly affected by changes in broad stock prices: they have a negative (positive) long-run relationship with the medium (small) capitalization index. In absolute terms, the ordering of the coefficients for the oil and gas exploration and production index is the same than that of the integrated oil and gas index (although with contrasting signs). Since the opposite sign on the mid- and small-cap indices is consistent but somewhat puzzling, we also examined the results of several different forms of our model, as well as using a variety of lag lengths. The sign results were consistent across the different models for both the daily and the weekly series.

The coefficients on the error-correction terms in the VEC models, shown in Table 5, represent the speed of adjustment to disturbances to long-run disequilibrium. For both oil sector models with weekly data, it is the oil price variable which adjusts to restore the long-run equilibrium. The other variables do not adjust significantly. For the integrated oil and gas index model the response is inverse, while for the oil and gas exploration and production index model the response is direct. The stock market indices do not have significant coefficients of adjustment for either oil sector index. This implies that the relationship of the broad stock market prices to the stock prices of companies in the oil and gas industry is of a long-run rather than a short-run nature.

Table 5. Vector Error-Correction (VEC) Model

\begin{tabular}{llllll}
\hline \multicolumn{6}{l}{ Panel A: Coefficients of Error-Correction Term for the Integrated Oil and Gas Index } \\
\hline D(LINTEG) & D(LEXPL) & D(LOILS) & D(LLCAP) & D(LMCAP) & D(LSCAP) \\
-0.003 & 0.003 & $-0.027^{* *}$ & -0.005 & -0.007 & -0.006 \\
$(-0.812)$ & $(0.491)$ & $(-3.523)$ & $(-1.404)$ & $(-1.753)$ & $(-1.398)$ \\
\hline \multicolumn{5}{l}{ Panel B: Coefficients of Error-Correction Term for the Oil and Gas Exploration \& Production Index } \\
\hline D(LINTEG) & D(LEXPL) & D(LOILS) & D(LLCAP) & D(LMCAP) & D(LSCAP) \\
-0.005 & 0.006 & $0.043^{* *}$ & 0.008 & 0.011 & 0.010 \\
$(-0.491)$ & $(0.812)$ & $(3.523)$ & $(1.404)$ & $(1.753)$ & $(1.400)$ \\
\hline
\end{tabular}

Figures in brackets are $\mathrm{t}$ statistics.

** Significant at the 5 percent level.

Variance decompositions of the forecast errors are also used to further examine the nature of the short-term relationships in the OIL grouping model. Variance decompositions measure the proportion of the forecast error variance of each series that is explained by its own innovations and by innovations from the other series in the grouping. There is a lesser degree of interdependence (or a greater degree of independence) when a series is shocked and a greater (lesser) proportion of its forecast error variance can be attributed to its own innovation rather than innovations from the other series. We report results at horizons of 1, 13, 26, 39, and 52 weeks for the oil sector price indices in Table 6. (Note 5) Both oil sector indices explain a very large proportion of the forecast error variance by their own innovations, as opposed to innovations from the other series. However, both oil sector indices are affected 
by innovations in the mid-cap index and to a smaller degree, by innovations in the oil price index. In addition, the integrated oil and gas index is affected by innovations in the oil and gas exploration and production index while the oil and gas exploration and production index is impacted by innovations in the small-cap index. The large-cap index has comparatively little effect on either of the oil sector indices. Overall, the variance decomposition results are consistent with the results of the VEC model.

Table 6. Variance decomposition results for the weekly VEC model

\begin{tabular}{|c|c|c|c|c|c|c|}
\hline \multicolumn{7}{|c|}{ a. Shocks to Integ } \\
\hline \multirow[t]{2}{*}{ Horizon } & \multicolumn{6}{|c|}{ Proportion of forecast error variance explained by shocks to } \\
\hline & INTEG & EXPL & OILS & LCAP & MCAP & SCAP \\
\hline \multicolumn{7}{|c|}{$\begin{array}{l}\text { Series explained - INTEG } \\
\text { weeks }\end{array}$} \\
\hline 1 & 100.00 & 0.000 & 0.000 & 0.000 & 0.000 & 0.000 \\
\hline 13 & 99.348 & 0.060 & 0.141 & 0.068 & 0.337 & 0.045 \\
\hline 26 & 99.342 & 0.157 & 0.079 & 0.044 & 0.351 & 0.026 \\
\hline 39 & 99.175 & 0.293 & 0.102 & 0.030 & 0.363 & 0.037 \\
\hline 52 & 98.882 & 0.453 & 0.200 & 0.025 & 0.373 & 0.066 \\
\hline \multicolumn{7}{|c|}{ b. Shocks to Expl } \\
\hline \multirow[t]{2}{*}{ Horizon } & \multicolumn{6}{|c|}{ Proportion of forecast error variance explained by shocks to } \\
\hline & EXPL & INTEG & OILS & LCAP & MCAP & SCAP \\
\hline \multicolumn{7}{|c|}{$\begin{array}{l}\text { Series explained - EXPL } \\
\text { weeks }\end{array}$} \\
\hline 1 & 100.00 & 0.000 & 0.000 & 0.000 & 0.000 & 0.000 \\
\hline 13 & 99.151 & 0.149 & 0.025 & 0.017 & 0.372 & 0.286 \\
\hline 26 & 99.136 & 0.125 & 0.085 & 0.019 & 0.392 & 0.242 \\
\hline 39 & 99.111 & 0.107 & 0.150 & 0.020 & 0.413 & 0.208 \\
\hline 52 & 99.081 & 0.095 & 0.209 & 0.020 & 0.410 & 0.183 \\
\hline
\end{tabular}

Note: In percentage terms - rows may not sum to 100 due to rounding error.

\section{Conclusion and Recommendation}

This paper investigates the dynamic relationships between WTI crude oil (spot or futures) prices, two oil sector stock price indices and three stock market price indices representing large, mid and small capitalization stocks, referred to as the OIL grouping model, over the 1996-2010 time period. Multivariate cointegration tests are performed to investigate long-term comovements between the series, while allowing for the possibility of short-run divergences. Variance decompositions are also employed to describe the long- and short-run dynamics of the series.

One cointegrating relationship between the series in the model is found, indicating long-run interdependence between them (and reduced benefits from diversification). A vector error-correction (VEC) model reveals that the stock prices of companies in the integrated oil and gas sector have a long-run negative relationship with oil prices but a more significant positive relationship to the stock prices of companies in the S\&P mid-cap index while those in the oil and gas exploration and production sector have a long-run positive relationship with oil prices but a more significant positive relationship to the stock price of companies in the S\&P small-cap index. However, following shocks to both oil sector indices, it is the oil price series which tends to restore the long-term equilibrium in the OIL grouping model. Variance decompositions indicate that both oil sector indices are affected by innovations in the mid-cap index and to a smaller degree, by innovations in the oil price index. These findings should be useful to investors in their attempts at appropriately structure their overall portfolios. More specifically, a decrease (increase) in oil prices may prompt investors to become interested in investing in the stock of companies in the refining and 
marketing or downstream (exploration and production or upstream) sector of the oil and gas industry, especially if they expect broad U.S. stock market prices to increase in the long run.

\section{References}

Al-Mudhaf, A., \& Goodwin, T. H. (1993). Oil shocks and oil stocks: evidence from the 1970s. Applied Economics, $25,181-190$.

Arouri, M., \& Rault, C. (2010). Oil prices and stock markets: what drives what in the Gulf Corporation Council countries? CESifo working paper, No. 2934.

Hammoudeh, S., \& Eleisa. E. (2004). Dynamic relationships among GCC stock markets and NYMEX oil futures. Contemporary Economic Policy, 22, 250-269.

Hammoudeh, S., Dibooglu, S., \& Aleisa, E. (2004). Relationships among U.S. oil prices and oil industry equity indices. International Review of Economics and Finance, 13, 427-453.

Hammoudeh, S., Li, H., \& Jeon, B. (2003). Causality and volatility spillovers among petroleum prices of WTI, gasoline and heating oil in different locations. The North American Journal of Economics and Finance, 14, $89-114$.

Huang, R., Masulis, R., \& Stoll, H. (1996). Energy shocks and financial markets. Journal of Futures Markets, 16, $1-27$.

Kilian, L., \& Park, C. (2009). The impact of oil price shocks on the U.S. stock market. International Economic Review, 50, 1267-1287.

Maghyereh, A. (2004). Oil price shocks and emerging stock markets: a generalized VAR approach. International Journal of Applied Econometrics and Quantitative Studies, 1, 27-40.

Maghyereh, A., \& Al-Kandari, A. (2007). Oil prices and stock markets in GCC countries: new evidence from nonlinear cointegration analysis. Managerial Finance, 33, 449-460.

Papapetrou, E. (2001). Oil price shocks, stock markets, economic activity and employment in Greece. Energy Economics, 23, 511-532.

Sadorsky, P. (1999). Oil price shocks and stock market activity. Energy Economics, 21, 449-469.

\section{Notes}

Note 1. See Hammoudeh, Dibooglu, and Aleisa (2003) for a review of the relationships among oil spot and futures prices.

Note 2. Kilian and Park (2009) find that the conventional wisdom that higher oil prices necessary cause lower stock prices applies only when the increase in the price of crude oil reflects fears about the future availability of oil supplies. In contrast, if higher oil prices are driven by a global economic expansion, higher stock prices are found.

Note 3. The results for the daily returns series are very similar to the weekly series and are not reported to conserve space. Similarly, the results using the oil future price series are identical to those using the oil spot price series and are not reported. These results are available from the authors upon request.

Note 4 . The results of the bivariate $(2 \times 2)$ and multivariate $(3 \times 3,4 \times 4$ and $5 \times 5)$ cointegration tests are not reported to save space but are available upon request from the authors. We do not also report the multivariate cointegration test results involving the oil future price index (OILF) with each oil sector price series (INTEG and EXPL) and the three stock market price indices (LCAP, MCAP, and SCAP) as they are nearly identical to those involving the oil spot price series (OILS).

Note 5. Since the results depend to some extent on the ordering of the series, different orderings were compared; the qualitative results were similar, particularly at the longer horizons.

\section{Appendix}

This appendix presents some of the mathematical details of cointegration theory. If there are two variables, $\mathrm{x}_{\mathrm{t}}$ and $\mathrm{y}_{\mathrm{t}}$, which are both nonstationary in levels but stationary in first differences, then $\mathrm{x}_{\mathrm{t}}$ and $\mathrm{y}_{\mathrm{t}}$ are integrated of order one, $\mathrm{I}(1)$, and their linear combination having the form 


$$
z_{t}=x_{t}-a y_{t}
$$

is generally also $I(1)$. However, if there is an (a) such that $z_{t}$ is integrated of order zero, $I(0)$, the linear combination of $x_{t}$ and $y_{t}$ is stationary and the two variables are said to be cointegrated (Engle and Granger, 1987). If two variables are cointegrated, there is an underlying long-run relationship between them. In the short run the series may drift apart, but if they are cointegrated, they will move toward long-run equilibrium through the error-correction mechanism.

The first step in the analysis is to test each series for the presence of unit roots. This can be done by means of the Augmented Dickey Fuller (ADF) test, an extension of the Dickey and Fuller (1981) method. The ADF test uses a regression of the first differences of the series against the series lagged once, and lagged difference terms, with optional constant and time trend terms:

$$
\Delta \mathrm{y}_{\mathrm{t}}=\mathrm{a}_{0}+\mathrm{a}_{1} \mathrm{t}+\gamma \mathrm{y}_{\mathrm{t}-1}+\Sigma \mathrm{b}_{\mathrm{i}} \mathrm{y}_{\mathrm{t}-\mathrm{i}+1}+\mathrm{e}_{\mathrm{t}}
$$

In the equation $\Delta$ is the first difference operator, $\mathrm{a}_{0}$ is an intercept, $\mathrm{a}_{1} \mathrm{t}$ is a linear time trend, $\mathrm{e}_{\mathrm{t}}$ is an error term, and $\mathrm{i}$ is the number of lagged first-differenced terms such that $e_{t}$ is white noise. The test for a unit root has the null hypothesis that $\gamma=0$. If the coefficient is significantly different from zero, the hypothesis that $\mathrm{y}_{\mathrm{t}}$ contains a unit root is rejected. If the test on the level series fails to reject, the ADF procedure is then applied to the first-differences of the series. Rejection leads to the conclusion that the series is integrated of order one, I(1).

A limitation of the Dickey-Fuller test is that it assumes that the errors are statistically independent and have a constant variance. In 1988, Phillips and Perron (PP) generalized the ADF test:

$$
\mathrm{y}_{\mathrm{t}}=\mathrm{b}_{0}+\mathrm{b}_{1} \mathrm{y}_{\mathrm{t}-1}+\mathrm{b}_{2}(\mathrm{t}-\mathrm{T} / 2)+\mu_{\mathrm{t}}
$$

$\mathrm{T}$ is the number of observations and the disturbance term $\mu_{\mathrm{t}}$ is such that $\mathrm{E}\left(\mu_{\mathrm{t}}\right)=0$, but there is no requirement that the disturbance term is serially uncorrelated or homogeneous. The equation is estimated by ordinary least squares and the t-statistic of the $b_{1}$ coefficient is corrected for serial correlation in $\mu_{t}$ using the Newey-West (1987) procedure for adjusting the standard errors.

The Johansen (1988) approach to testing for cointegration relies on the relationship between the rank of a matrix and its characteristic roots, or eigenvalues. Let $X_{t}$ be a vector of $n$ time series variables, each of which is integrated of order (1), and assume that $X_{t}$ can be modeled by a vector autoregression (VAR):

$$
\mathrm{X}_{\mathrm{t}}=\mathrm{A}_{1} \mathrm{X}_{\mathrm{t}-1}+\ldots+\mathrm{A}_{\mathrm{p}} \mathrm{X}_{\mathrm{t}-\mathrm{p}}+\varepsilon_{\mathrm{t}}
$$

Rewrite the VAR as

$$
\Delta \mathrm{x}_{\mathrm{t}}=\Pi \mathrm{x}_{\mathrm{t}-1}+\Sigma \Gamma \Delta \mathrm{x}_{\mathrm{t}-\mathrm{i}}+\varepsilon_{\mathrm{t}}
$$

where $\Pi=\sum \mathrm{A}_{\mathrm{i}}-\mathrm{I}, \Gamma_{\mathrm{i}}=-\sum \mathrm{A}_{\mathrm{i}}$. If the coefficient matrix $\Pi$ has reduced rank $\mathrm{r}<\mathrm{k}$, there exist $\mathrm{k} x \mathrm{r}$ matrices $\alpha$ and $\beta$ each with rank $r$ such that $\Pi=\alpha \beta^{\prime}$ and $\beta^{\prime} x_{t}$ is stationary. The number of cointegrating relations is given by $r$, and each column of $\beta$ is a cointegrating vector. Three cases are possible. First, if $\Pi$ is of full rank, all elements of $X$ are stationary, and none of the series has a unit root. Second, if the rank of $\Pi=0$, there are no combinations which are stationary and there are no cointegrating vectors. Third, if the rank of $\Pi$ is $r$ such that $0<r$ $<\mathrm{k}$, then the $\mathrm{X}$ variables are cointegrated and there exist $\mathrm{r}$ cointegrating vectors. Equation (5) can be modified to allow for an intercept and a linear trend.

The number of distinct cointegrating vectors can be obtained by determining the significance of the characteristic roots of $\Pi$. To identify the number of characteristic roots that are not different from unity we use two statistics, the trace test and the maximum eigenvalue test:

$$
\lambda_{\text {trace }}(\mathrm{r})=-\mathrm{T} \sum \ln \left(1-\lambda_{\mathrm{i}}\right)
$$

and

$$
\lambda_{\max }(\mathrm{r}, \mathrm{r}+1)=-\mathrm{T} \ln \left(1-\lambda_{\mathrm{r}+1}\right)
$$

where $\lambda_{\mathrm{i}}=$ the estimated values of the characteristic roots (eigenvalues) obtained from the estimated $\Pi$ matrix, $\mathrm{r}$ is the number of cointegrating vectors, and $\mathrm{T}=$ the number of usable observations. The trace test evaluates the null hypothesis that the number of distinct cointegrating vectors is less than or equal to $r$ against a general alternative. The maximum eigenvalue test examines the number of cointegrating vectors versus that number plus one. If the variables in $X_{t}$ are not cointegrated, the rank of $\Pi$ is zero and all the characteristic roots are zero. Since $\ln (1)=0$, each of the expressions $\ln \left(1-\lambda_{i}\right)$ will equal zero in that case. Critical values for the test are provided by Johansen and Juselius (1990) and by Osterwald-Lenum (1992). 